\title{
Compartilhamento e aquisição de competências na estratégia da Empresa Brasileira de Correios e Telégrafos
}

\author{
Leonel Mazzalia,*, Maria Carolina de Azevedo Ferreira de Souza ${ }^{b}$, \\ Hélio Rubens Oliveira das Neves ${ }^{\mathrm{c}}$ \\ a,*leonel_mazzali@uol.com.br, USCS, Brasil \\ bcarols@eco.unicamp.br, UNICAMP, Brasil \\ cprofheliorubens@yahoo.com.br, EBCT, Brasil
}

\begin{abstract}
Resumo
Tendo por referência a proposição de Frechet e Pardo (2005), o trabalho é um estudo explanatório que aborda a estratégia de diversificação da Empresa Brasileira de Correios e Telégrafos (ECT), analisando como o portfólio de recursos influencia e é influenciado pelas decisões de entrada em novos domínios. Trata-se de um estudo de caso assentado no levantamento de ativos tangiveis e intangíveis e na avaliação dos efeitos da atuação em novos segmentos sobre o faturamento da empresa. 0 estudo confirma a proposição dos autores de referência, apontando para duas lógicas imanentes ao processo de diversificação: utilização de recursos preexistentes para entrar em novos produtos/mercados e para o desenvolvimento de novos recursos. Ademais, pode-se argumentar que um fator dinâmico crucial na evolução da corporação é a interdependência ou interação no tempo entre a diversificação de negócios relacionada aos recursos e a diversificação de recursos.
\end{abstract}

Palavras-chave

Estratégia. Diversificação. Competências dinâmicas.

\section{Introdução}

Uma questão central no estudo do processo de diversificação é a que determina a sua direção. A proximidade setorial entre a atividade inicial e a atividade visada constitui o principal critério estrutural da tipologia clássica das estratégias de diversificação: relacionada e não relacionada ou conglomerada. Na primeira, a marca é a exploração das inter-relações entre produtos e mercados, tendo por base o compartilhamento de ativos ou a transferência de competências entre distintas unidades estratégicas de negócio; na diversificação não relacionada, o setor visado não guarda nenhum ponto em comum com a atividade de origem, tendo por base a busca de sinergias financeiras associadas à redução do custo de capital e à redução do risco.

A partir do estudo de Rumelt (1974), vários trabalhos centrados na denominada visão da empresa baseada nos recursos procuraram mostrar a superioridade da estratégia de diversificação relacionada, emergindo a contribuição de Frechet e Pardo (2005), propondo analisar a diversificação relacionada por meio de duas perspectivas: exploração dos recursos existentes e aquisição e desenvolvimento de novos conhecimentos e competências.

Tendo por referência a proposição dos referidos autores, este trabalho tem por objetivo analisar em profundidade a estratégia de diversificação da Empresa Brasileira de Correios e Telégrafos (ECT), investigando como o portfólio de recursos/ competências influencia e é influenciado pelas decisões de entrada em novos domínios - produtos, mercados e tecnologias. É um estudo explanatório que se utiliza do método do estudo de caso para a avaliação longitudinal do processo de diversificação identificação do portfólio de recursos/competências e de sua relação com o tipo e a natureza dos novos segmentos de atuação. 
A escolha da estratégia de diversificação da ECT como objeto de investigação se deve ao fato de estar associada a significativas alterações institucionais atreladas à denominada Reforma do Setor Postal, no período compreendido entre 1995 e 2006. No início da década de 1990, a política para o setor postal foi alterada e a empresa elaborou o Projeto Correios 2000, no qual se fez ampla análise prospectiva do ambiente no qual se inseria e foi traçado o plano estratégico para os anos 2000. As diretrizes foram a universalização dos serviços e a introdução da competição no setor, estimulando o desenvolvimento de novos produtos/serviços articulados às atividades econômicas, em particular malote corporativo, marketing direto, certificação digital, logística integrada e serviços bancários.

0 trabalho está estruturado em sete seções. A primeira é introdutória. A segunda discute as bases da estratégia de diversificação da perspectiva da visão da empresa baseada em recursos, introduzindo a abordagem proposta por Frechet e Pardo (2005) e sua fundamentação no denominado "enfoque das competências dinâmicas”. A terceira apresenta os procedimentos metodológicos da pesquisa empreendida. A quarta seção mostra a estratégia de diversificação perseguida pela ECT no período 1995-2006. A quinta analisa a referida estratégia da perspectiva do portfólio de recursos e competências e a sexta evidencia os resultados alcançados. Finalmente, na sétima, algumas conclusões são indicadas e apresentadas possibilidades para futuras pesquisas.

\section{Visão da empresa baseada em recursos e bases da estratégia de diversificação}

A visão da empresa baseada em recursos, originária da contribuição seminal de Penrose (2006), propõe que os recursos específicos à empresa, convertidos, de uma forma particular, em produtos e serviços, e acumulados ao longo de sua história, determinam as suas possibilidades de crescimento. Recursos e serviços produtivos não utilizados (em excesso) agem, se identificados e explorados, como força seletiva e determinante na direção da expansão. Tal expansão tem como eixo a busca e exploração de oportunidades na expectativa de ampliação da rentabilidade, caracterizando uma determinada estratégia de crescimento. A diversificação é uma estratégia de expansão decorrente dessas possibilidades, tendo como base o compartilhamento de recursos (sinergia) entre atuais e novos negócios (PETERAF, 1993). As oportunidades de sinergia emergem no âmbito dos recursos tangiveis e, particularmente, dos intangíveis, associados aos conhecimentos tecnológicos e comerciais.

Segundo essa abordagem, o perfil de recursos é crítico para prever as características dos novos domínios, objeto da decisão de diversificação. 0 ponto crucial, portanto, é a percepção de que os recursos ociosos, em vez de serem vistos como principal motivação e alvo de uma reestruturação, podem ser a base de um desafio para inovar, um incentivo para a expansão e uma fonte de vantagens competitivas.

Os recursos "em excesso" são mais frequentemente empregados em contextos similares ou relacionados. Esse aspecto foi salientado por Steindl (1983), em uma de suas principais hipóteses na clássica análise sobre a acumulação e o padrão de concorrência no interior de uma indústria. 0 autor não exclui a possibilidade de investimentos na direção da diversificação para novas indústrias, mas aponta as restrições e os esforços adicionais que serão requeridos.

Apesar dessas dificuldades, mesmo em situações em que o mercado de origem não está estagnado, a diversificação pode ser uma estratégia a ser adotada como meio de fortalecer as condições de concorrência da empresa e seu poder de mercado. Por outro lado, quando reduzidas as possibilidades de expansão no mercado de origem, a diversificação para novas indústrias passa a ser uma opção ainda mais relevante, em especial se associada ao aproveitamento de recursos que de outra forma ficariam ociosos.

0 conceito de "proximidade" ou relacionamento entre atividades refere-se, de modo geral, à aplicabilidade, em novos negócios, dos recursos que a empresa possui. Insere-se aí a noção de expansão coerente, que se relaciona com a área de especialização da empresa, nos termos de Penrose (2006). A noção de coerência corporativa encontra-se também em Teece et al. (1994), cuja referência é a habilidade de a empresa gerar e explorar sinergias de vários tipos, as quais surgem com base nos recursos e nas competências, e não somente no âmbito de produtos/mercados. É importante ressaltar que, embora conceitualmente a noção de coerência corporativa tenha fundamentalmente a ver com os recursos e as competências da empresa, a sua operacionalização ocorre associando o conceito de "proximidade" às características das linhas de produtos. Só mais recentemente, como apontam Fan e lang (2000), a diversificação relacionada passou a ser avaliada a partir da similaridade dos recursos. 
Da perspectiva dos recursos, mesmo que os mercados e os produtos sejam distintos, existe um link entre eles a partir do compartilhamento de recursos. Esse aspecto pode ser encontrado também em Penrose (2006), que apontou a relevância dos recursos disponíveis na empresa mesmo quando a diversificação requer o estabelecimento de uma nova base produtiva.

Frechet e Pardo (2005) aprofundam a discussão a partir da consideração de duas perspectivas de análise da estratégia de diversificação relacionada. Em primeiro lugar, a diversificação se expressa em novas formas de exploração dos recursos existentes. Em segundo, a diversificação tem como orientação a obtenção de recursos que a empresa ainda não possui, isto é, constitui um meio para construir novos recursos e competências. Para Markides e Williamson (1994), o maior benefício da diversificação a longo prazo é a sua contribuição para a criação e/ou acumulação de novos recursos estratégicos.

Segundo a primeira perspectiva, o portfólio de recursos e competências delimita as possibilidades de diversificação. A referência é a ideia dos recursos "em excesso" como força propulsora da diversificação. Na segunda perspectiva, a aprendizagem é a base racional da estratégia de diversificação, impactando o processo de acumulação de recursos. De um lado, a diversificação irá fortalecer as "competências nucleares" da empresa e, de outro, assegurar a heterogeneidade da empresa no âmbito dos recursos, tendo por base a exploração de novos domínios do conhecimento - tecnologias e novas competências (MILLER, 2004).

A segunda perspectiva está relacionada ao conceito de "diversificação tecnológica". Para Granstrand e Oskarsson (1994), a diversificação tecnológica se refere à expansão das competências da empresa, ao aumento da complexidade dos produtos e às interdependências entre tecnologias incorporadas aos produtos.

As duas perspectivas estão inseridas, respectivamente, nas duas formulações da visão da empresa baseada em recursos, denominadas por Foss (1997) de "enfoque tradicional" e "enfoque das competências dinâmicas e das competências nucleares".

De acordo com o enfoque das competências dinâmicas e das competências nucleares, o processo de crescimento apoia-se em uma base renovável de recursos (TEECE; PISANO; SHUEN, 1997). Uma estratégia gerará, no tempo presente, ativos intangiveis suficientes para assegurar que o seu estoque acumulado permita à empresa tornar a sua estratégia futura viável. Em síntese, o conhecimento como um recurso estratégico necessário para a empresa renovar a sua base de recursos e gerar novas bases.

No âmbito da relação entre estratégia de diversificação e performance, Dess et al. (1995), após extensa revisão dos principais trabalhos, não chegam a um consenso. Os trabalhos de Rumelt (1974, 1982), Bettis e Mahajan (1985), Palepu (1985), Hitt e lreland (1986), Wernerfelt e Montgomery (1988) e Hamilton e Shergill (1993) analisaram a influência da estratégia de diversificação sobre os resultados, mostrando a superioridade da diversificação relacionada em relação à denominada diversificação “não relacionada”. Ramanujam e Varadarajan (1989) sugerem, no entanto, que a atemporalidade dos dados obtidos, em geral por meio de levantamento do tipo cross section, é insuficiente para determinar a relação entre diversificação e resultados.

Embora não encontrem diferenças significativas nos resultados entre empresas diversificadas e não diversificadas, McDougall e Round (1984) apontam para o fato de que a diversificação baseada na tecnologia apresenta performance superior; a combinação entre oportunidades tecnológicas e diversificação produz melhores resultados. Da mesma forma, os trabalhos de Granstrand, Sjolander e Alange (1989) e Granstrand e Sjolander (1990) apontaram a importância da diversificação tecnológica para o crescimento e para a diversificação de produtos/mercados.

Analisando o padrão de diversificação das maiores empresas americanas e europeias listadas entre as 500 maiores da revista Fortune, no período 1984-1992, Gambardella e Torrisi (1998) verificaram que a performance econômica financeira superior está associada à focalização no core business e na ampliação das competências tecnológicas.

Em síntese, nas palavras de Piscitello (2004, p. 763):

Sustentamos que a análise da relação entre a diversificação corporativa e a performance requer que ambos os lados - o negócio e o tecnológico, isto é, mudanças na base de produtos e na base tecnológica - devem ser considerados. Embora essas mudanças possam ocorrer de forma independente, os benefícios econômicos podem ser fortemente estimulados quando se combinam.

\section{Procedimentos metodológicos}

A pesquisa é do tipo explanatório e utiliza o estudo de caso como estratégia de levantamento e análise de dados. Para Yin (2001, p.25), no âmbito da pesquisa em ciências sociais: 
[...] questões do tipo "como" e "por que" são mais explanatórias, e é provável que levem ao uso de estudos de casos, pesquisas históricas e experimentos como estratégias de pesquisa escolhidas. lsso se deve ao fato de que tais questões lidam com ligações operacionais que necessitam ser traçadas ao longo do tempo, em vez de serem encaradas como meras repetições ou incidências.

Ademais, para o referido autor.

o estudo de caso é a estratégia escolhida ao se examinarem acontecimentos contemporâneos, mas quando não se podem manipular comportamentos relevantes (YIN, 2001, p. 27).

A Empresa Brasileira de Correios e Telégrafos apresenta-se como objeto privilegiado de análise, tendo em vista as profundas mudanças na sua estratégia de atuação. A partir da década de 1990, deixou de ser um agente exclusivamente do setor postal; abriu seu leque de serviços, assumiu características de "banco de serviços" e comportamento mercadológico agressivo, buscando vantagem competitiva no mercado dos serviços não monopolizados, em particular no âmbito da logística integrada.

A unidade de análise do estudo de caso é a estratégia de diversificação da ECT, levada a efeito no período 1995-2006, enfocando a identificação do tipo e da natureza dos recursos/das competências e de sua relação com os novos segmentos de atuação. 0 procedimento básico de coleta de dados foi a pesquisa documental, tendo em vista o acesso a relatórios da ECT $(1995,1996,1997,1998$, 1999, 2000, 2001, 2002, 2003, 2004, 2005, 2006), Estrutura da ECT (ECT, 1995), Plano estratégico para o período 2000-2005 (ECT, 1999), Plano estratégico 2004-2007 (ECT, 2007) e Planejamento estratégico 2008-2017 (ECT, 2007b) - e o relatório da empresa de consultoria Bain \& Company (2003), que teve como objetivo o estudo de viabilidade para atuação da ECT em logística integrada. Esses documentos possibilitaram a coleta de informações valiosas sobre as decisões estratégicas da ECT no período de análise, tomando-se, no entanto, os devidos cuidados diante da observação de Yin (2001, p.109):

Na verdade, os documentos devem ser cuidadosamente utilizados e não se deve tomá-los como registros literais de eventos que ocorreram

0 estabelecimento de medidas operacionais consistentes (validade do constructo) para os conceitos "recursos" e "competências" representa um desafio metodológico, apontado por Barney, Wright e Ketchen (2001). Nessa direção, foi realizado um extenso estudo dos ativos tangíveis (terrenos, áreas cobertas, transporte de longa distância, transporte de "última milha", agências e sistemas de informação) e ativos intangíveis (pessoal, habilidades, processos, relações comerciais e imagem da marca), visando identificar o portfólio de recursos e competências.

Embora a rentabilidade (retorno sobre o patrimônio líquido) e o aumento nas vendas sejam considerados por Hamilton e Shergill (1993) como indicadores centrais da performance dos negócios, a pesquisa se restringe à utilização do aumento na receita como medida do impacto do processo de diversificação. Essa opção que, obviamente, limita o alcance da análise se deve, de um lado, ao fato de não ter sido possível obter dados desagregados do lucro segundo atividades tradicionais e atividades resultantes da diversificação e, de outro, devido à influência da política de tarifas postais sobre os resultados da empresa.

Finalmente, a análise cronológica de acontecimentos atrelados ao processo de diversificação foi a base da estratégia analítica das evidências obtidas dos documentos coletados no estudo de caso, pois

[...] permite que o pesquisador determine os eventos
causais ao longo do tempo, uma vez que a sequência
básica de uma causa e seu efeito não pode ser
temporalmente invertida. [...] O objetivo, do ponto de
vista analítico, é comparar essa cronologia com aquela
prevista por alguma teoria explanatória (YIN, 2001,
p. 147).

A proposição de Frechet e Pardo (2005) orientou a interpretação dos dados obtidos e definiu relações (explanações) por meio do foco na evolução, ao longo do tempo, do portfólio de recursos e na avaliação do potencial de compartilhamento de recursos e competências entre as operações tradicionais dos Correios (mensagem, encomendas, internacional e conveniência) e os novos segmentos de atuação (malote corporativo, marketing direto, certificação digital, logística integrada e Banco Postal).

\section{Processo de diversificação da empresa brasileira de correios e telégrafos}

no início da década de 1990, 92\% da receita da ECT estava concentrada nos denominados segmentos tradicionais, abrangendo mensagem (cartas e impressos simples, franqueamento, telemáticos e correio híbrido postal), encomendas (Sedex, Sedex 10, Sedex Hoje e reembolso postal), filatelia, serviços e produtos de conveniência e internacional (exporta/importa fácil e mala direta internacional). A forte dependência desses segmentos foi resultado 
da estratégia seguida durante o período 19691994, cuja ênfase recaiu na integração nacional e na melhoria da qualidade dos serviços prestados - rapidez na entrega de correspondências. Desde a criação da Empresa Brasileira de Correios e Telégrafos, em 1969, houve a preocupação de desenvolver o sistema postal e telegráfico do país e incorporar os avanços tecnológicos. Foram criados o Serviço Especial de Entrega de Documentos (SEED), o Serviço de Entrega de Correspondência Agrupada (SERCA) e os Serviços Expressos (SEDEX).

0 esquema operacional da empresa para 0 atendimento dos serviços de correio convencional seria relativamente simples, não fosse a grande extensão territorial e o número de objetos tratados, resultando numa logística complexa, que se inicia com a coleta pelas unidades de atendimento, para posterior seleção e direcionamento, segundo o destino, nos centros operacionais e, finalmente, a entrega. Em 1995, a ECT agregava 24 Diretorias Regionais (DRs) distribuídas em diferentes partes do país, correspondentes às áreas dos estados, com exceção do estado de São Paulo, dividido em duas regionais (SPM e SPI), da Diretoria Regional GT, englobando os estados de Goiás e Tocantins, e da Diretoria Regional NO, composta pelos seguintes estados: Amapá, Roraima, Acre e Rondônia. As DRs contavam com agências/unidades de atendimento, centros de distribuição domiciliar (carteiros) e centros operacionais (triagem e transbordo de objetos).

Em 1995, inspirado na Reforma do Setor Postal, foi elaborado o Projeto Correios 2000, com ampla análise prospectiva do ambiente da ECT e com estratégia para o período compreendido entre 1995 e 2005. Dentre as metas que deveriam ser implantadas gradualmente até 2005, merece destaque a redefinição dos negócios e a revisão do portfólio de produtos e serviços. A diversificação das atividades somente foi enfatizada a partir de 2000 , com base na percepção das potencialidades da oferta de novos serviços relacionados à entrega de malotes para pessoas jurídicas, ao marketing direto, ao Banco Postal, à logística integrada e à denominada certificação digital.

A entrega de malotes para pessoas jurídicas (malote corporativo) foi integralmente reformulada em 2000, com a criação de linhas exclusivas de coleta e personalização. 0 objetivo foi atender as necessidades de remessa expressa programada de correspondência agrupada entre unidades de uma mesma organização e entre unidades que integram a cadeia de suprimentos. Dentre os novos clientes, destacam-se Autolatina, Xerox do Brasil, IBM,
Hermes, Tubos e Conexões Tigre, Agrale, Grandene, Bradesco e ltaú.

Outro segmento explorado a partir de 2001 foi o marketing direto. Trata-se também de um conjunto de serviços prestado a pessoas jurídicas, visando atender as necessidades relacionadas à prospecção, à divulgação, à venda, à fidelização e ao relacionamento entre fornecedores e consumidores finais, por meio de soluções integradas. Dentre os serviços oferecidos destacam-se "mala direta agendada", "mala direta postal domiciliária" e "correios entrega direta".

A mala direta agendada é um serviço destinado à postagem de mala direta com data ou período de entrega preestabelecido pelo remetente, contemplando captação/postagem, manuseio, transferência, tratamento, interiorização e entrega, com fornecimento de informações via web. A mala direta domiciliária é um serviço destinado à postagem de mídia sem endereçamento, com entrega segmentada ou aleatória, com o objetivo de atingir o público-alvo de interesse da organização-cliente. 0 "correios entrega direta" envolve um conjunto de soluções padronizadas e customizadas exclusivas para o segmento de publicações periódicas, com volume mínimo anual e informações gerenciais via web.

Além desses produtos, esforços foram sendo direcionados para a criação de um pacote de soluções baseadas em gestão de endereços, destinado a empresas que demandam normalização de cadastros de endereços para ações de marketing. Nesse campo, os principais serviços são: "diretório nacional de endereços (DNE)”, "serviços de endereços", "guia postal brasileiro eletrônico com endereçador" e "serviços de resposta".

A ECT ingressou no segmento financeiro em 2002, com a criação do Banco Postal, constituído pelos serviços de correspondente bancário, serviços financeiros postais convencionais (vale-postal nacional e internacional e cheque correios) e outros serviços financeiros correlatos ou afins, como o carnê do Baú e Telesena.

Em 2002, foi criada área de negócios específica para atender o mercado de logística integrada, um dos segmentos que mais crescem nas grandes empresas de serviço postal do mundo. No Brasil, os fornecedores de serviços logísticos são, em grande parte, empresas que executam atividades isoladas de transporte, armazenagem ou movimentação, não operando, portanto, a logística de seus clientes de forma integrada. Apenas uma parcela desse mercado é formada por típicos operadores logísticos. 
A União Postal Universal - UPU - e a Bain \& Company (2003) firmaram, em julho de 2001, um contrato para desenvolvimento de estudos de viabilidade da potencial atuação da ECT em atividades de logística integrada. A partir daí foi definida a estratégia competitiva da ECT no negócio de logística, delimitando os segmentos prioritários, os produtos, a estrutura operacional e a organização necessária. Tendo por referência a identificação dos setores mais atrativos, estes foram agrupados em "cinco iniciativas" coerentes com o desenvolvimento estratégico da ECT. A estratégia foi desenvolvida visando oferecer soluções logísticas completas e customizadas a cada cliente.

Para os segmentos integrados pelas operadoras de telefonia celular e pelas empresas do e-commerce/vendas por catálogo, a ECT propôs uma solução completa para o gerenciamento da logística, oferecendo os serviços de recebimento, armazenagem, programação do pré-pago, picking, packing, expedição e distribuição. As únicas etapas da cadeia logística das operadoras não contempladas são compras e atendimento aos clientes.

Para o segmento das empresas de vendas diretas com representantes (ou "consultoras de vendas"), como Avon, Natura e Hermes, a solução proposta vislumbrava uma gestão parcial da cadeia de valor, não englobando o armazenamento e com ênfase nos processos administrativos dos clientes. 0 objetivo era agilizar o processo de captação de pedidos, os pagamentos e a logística reversa, oferecendo um serviço de distribuição expressa mais eficiente. Toda a gama de serviços foi disponibilizada aos clientes finais e aos representantes das empresas clientes através de sites de compra na internet.

No denominado hub logístico, tratou-se de absorver a logística de empresas que participam de negócios nos quais há grande pulverização na fabricação e no varejo, com intermediação (ou participação de atacadistas e/ou distribuidores) não muito marcante. Livros e calçados são dois setores que se destacam. 0 valor oferecido ao cliente pela ECT refere-se aos ganhos no custo e no nível do serviço por meio da consolidação das cargas de diferentes clientes, sendo responsável pelos transportes de transferência e de distribuição, pela logística de retorno e pelas atividades de armazenagem e fulfilment.

Às empresas de high tech e de eletroeletrônicos a ECT ofereceu uma solução abrangente para a logística de peças de reposição, com o objetivo de reduzir o ciclo total da peça (incluindo a logística reversa da peça defeituosa). A minimização dos leadtimes, tanto de entrega quanto de retorno, foi alcançada por meio da utilização de serviços de transporte de alta velocidade somados a um sistema de processamento de pedidos eficaz em armazéns bem posicionados.

Finalmente, em 2004, o serviço de Certificação Digital foi disponibilizado em três agências - uma em São Paulo e duas em Brasília. As três agências designadas como piloto comercializam certificados digitais $e$-CPF e $e$-CNPJ.

Como se percebe, a Reforma do Setor Postal foi decisiva para a viabilização de novos e importantes campos de atuação da ECT, porém as bases para a entrada em novos produtos (serviços)/mercados, isto é, para a consolidação da estratégia de diversificação, já estavam criadas, conforme será demonstrado na seção a seguir.

\section{A estratégia de diversificação da ECT da perspectiva do portfólio de recursos e competências}

No início da década de 1990, ampla cobertura geográfica, habilidades em transporte e entrega de correspondência e encomendas constituíam a base da competitividade da ECT, conforme ilustrado no Quadro 1. A empresa passou a deter a maior cadeia de lojas de atendimento do país, com alcance nos pontos mais remotos e excelência em algumas etapas-chave de transporte, como roteirização/ preparação da entrega de "última milha" (last mile) - rede eficiente para entrega/coleta aos clientes finais -, "rastreamento fino" (muitos pontos de controle) das entregas e sistema de rastreamento de objetos - 3 mil coletores de dados espalhados nos centros operacionais do país.

Quadro 1. Estrutura da ECT (início da década de 1990).

\begin{tabular}{|c|c|}
\hline & Quantidade \\
\hline Agência de Correios & 11.713 \\
\hline Caixas de Coleta & 25.432 \\
\hline Postos de Venda & 16.057 \\
\hline Caixas postais comunitárias & 101.001 \\
\hline Máquinas de autoatendimento & 246 \\
\hline Unidades de tratamento e distribuição & 741 \\
\hline Linhas de transporte aéreo & 28 \\
\hline Veículos & 5.586 \\
\hline Motocicletas & 5.585 \\
\hline Bicicletas & 25.017 \\
\hline Pessoal operacional & 82.582 \\
\hline Pessoal complementar & 19.902 \\
\hline Diretorias Regionais & 24 \\
\hline Regiões operacionais & 153 \\
\hline
\end{tabular}

Fonte: adaptado de ECT (2007). 
Um importante desdobramento da estratégia de integração nacional (1969-1994) foi a criação de uma rede de agências em todo o território nacional, que, em um primeiro momento, teve a função de capilaridade na captação e entrega de objetos postais. A partir de 1995, o conhecimento da realidade brasileira e a presença geográfica ímpar, aliados à capacidade de investimentos, se constituirão em uma vantagem competitiva para a entrada em novos segmentos.

Examinando os recursos necessários para a entrada nos segmentos representados por malote corporativo e marketing direto, constatou-se que, a não ser pela necessidade de estabelecer novos canais de relacionamento com os denominados clientes corporativos, eles estão atrelados ao sistema de coleta e entrega (rede de capilaridade) dos Correios. Mais precisamente, esses segmentos estão alinhados com os recursos/as competências preexistentes, constituindo-se na extensão dos serviços atuais para novos mercados (clientes corporativos). Vale destacar, no entanto, a incorporação de conhecimentos adicionais no âmbito da competência mercadológica. Em 2001, foi criado o Escritório de Consultoria em Marketing Direto (ECMD), que tem como objetivo, além da oferta dos serviços (mala direta agendada, mala direta postal domiciliária e correios entrega direta), a educação dos clientes corporativos para o uso do marketing direto.

Por sua vez, logística integrada, Banco Postal e certificação digital são segmentos em que, ao contrário do que seria de esperar, não acontece o pleno compartilhamento dos recursos e competências associados aos negócios tradicionais dos Correios.

As sinergias entre logística integrada, cartas e encomendas se limitam ao aproveitamento de poucos ativos (fixos e intangíveis) e à possibilidade de compartilhar uma pequena parcela das operações. Os ativos transferíveis para a logística são: imagem da marca Correios, algumas habilidades operacionais e alguns terrenos e imóveis vagos. Além disso, talvez seja possivel compartilhar, em alguns casos, o transporte através das redes nacionais e regionais, em linhas em que há disponibilidade de espaço.

Ativos relacionados com operações de última milha, áreas cobertas e relacionamentos comerciais são, na prática, não compartilháveis e foram duplicados para o negócio de logística integrada. A malha de coleta e entrega que, naturalmente, é visualizada como possuindo grandes sinergias com o negócio de logística não pode ser utilizada de forma significativa, devido a fortes limitadores, destacando-se rigidez de horários, limitado compartilhamento das paradas, limitados volumes disponiveis e complexidade operacional.

A frota de entrega tem grande rigidez de horários, diante das metas estabelecidas para os serviços externos (Sedex, Sedex 10 e malote corporativo) e para os serviços internos (agências, centros de tratamento e terminais de cargas), impedindo flexibilidade maior no número de paradas e/ou no tempo por parada.

A grande maioria das "paradas" dos serviços convencionais está concentrada em escritórios de grandes empresas, clientes residenciais e agências de serviços. Como as entregas de logística integrada acontecem, na maioria dos casos, no varejo ou em departamentos produtivos, é difícil o compartilhamento. Ademais, somente algumas linhas que servem os segmentos tradicionais têm nível baixo de ocupação no momento do pico; os veículos também têm limite de carga pouco adequado para entregas a grandes pontos de venda e/ou de distribuição. As exceções são as soluções de logística integrada para as empresas do e-commerce/vendas por catálogo e para as empresas de vendas diretas com representantes. Nesses dois casos, existem sinergias relevantes, de um lado, com os serviços Sedex/e-Sedex /encomenda normal e, de outro, com os serviços de coleta das devoluções e os serviços e-Sedex/Disque Sedex. Além disso, a capacitação no last mile pode ser compartilhada.

Finalmente, a logística integrada, de modo geral, apresenta um grau de complexidade operacional maior do que a entrega de malotes e Sedex: necessidade de aceitação da mercadoria pelo receptor, filas de espera, dificuldades de acesso às empresas, picos de volumes no final do mês e logística reversa (o cliente pode devolver a mercadoria). Além disso, os empregados teriam que ser treinados para operacionalizar dois processos muitos diferentes.

Com relação às competências totalmente inéditas para a ECT decorrentes da entrada no segmento de logística integrada, merece destaque a expertise na gestão de armazéns, operações correlatas e controle de inventários. Para o sistema de vendas diretas com representantes, de um lado, soluções da tecnologia da informação que viabilizam a colocação de pedidos e o pagamento por meio eletrônico e, de outro, centros de tratamento para lidar com os produtos devolvidos. Para o denominado hub logístico, uma rede primária para o transporte entre os fabricantes e o $h u b$ e uma rede de last mile para as entregas aos clientes finais. Na solução para a logística de peças de reposição (SPL - Service Parts Logistics), o sistema complexo para rastreamento das peças/ acompanhamento dos serviços e expertise na gestão 
de estoques de peças pequenas e de alto valor. No caso das empresas de telefonia celular, diante do elevado risco de roubo, não só o gerenciamento de empresas de segurança e seguradoras, mas também o GPS (Global Positioning System), para garantir maior segurança no processo de transporte de cargas.

Visando suprir competências associadas ao gerenciamento operacional e mercadológico, a ECT criou, no âmbito da Administração Central, o Departamento de Logística Integrada, um grupo de executivos e vendedores dedicado exclusivamente ao novo negócio. Esse grupo começará como departamento e futuramente se transformará em uma unidade de negócios autônoma. As principais competências em desenvolvimento são: inteligência logística, start-up, operações, tecnologia da informação e comercial. Nos relacionamentos comerciais, apesar de a ECT ter uma altíssima penetração nas grandes empresas do país, os contatos acontecem com gerentes do nível hierárquico intermediário. Esse tipo de interface não é adequado para a decisão de terceirização de grandes porções da cadeia logística da empresa-cliente. A venda de serviços de logística integrada é processo demorado que implica a tomada de decisões cruciais por parte da alta direção. Além disso, exige uma força de vendas capaz de compreender o modelo logístico do cliente e identificar oportunidades de melhoria.

Como a ECT não dispunha internamente de muitas das competências necessárias para lançar e gerir a atividade, efetivou parcerias estratégicas com a FedEx e com a TNT Logistics. A FedEx foi considerada altamente atrativa em função dos seguintes fatores: possuir know-how de logística integrada, ter grande credibilidade no mercado e estar extremamente interessada em desenvolver uma parceria com a ECT, para alavancar uma carteira de clientes corporativos. 0 interesse em ter a TNT como parceira se deve à grande credibilidade no mercado como operador logístico global.

AECT não possuía experiência no setor financeiro, recorrendo, em 2001, a uma parceria com o Banco do Brasil, para efetivar um projeto-piloto do Banco Postal em 36 agências dos Correios localizadas no interior do país. Com o término do projeto-piloto, em 2003, o Banco Brasileiro de Descontos S.A. foi selecionado como parceiro exclusivo de todas as 15 possibilidades de atendimento. A ECT repassa os recursos e o Bradesco se encarrega da manutenção e do gerenciamento das operações. As agências dos Correios atuam como correspondentes bancários ligados a uma agência do Bradesco.

A implantação do Banco Postal levou à criação do Departamento de Administração do Banco Postal (DEBAN) e à mudança do papel da tecnologia da informação, dado que, sem o uso dos modernos meios de comunicação e de softwares, não seria possível implantar serviços bancários em localidades distantes. Assim, para que as transações sejam processadas em tempo real, cada agência dos Correios passou a deter pelo menos uma antena parabólica e um terminal do Bradesco. Tendo em vista que "telecomunicação via satélite" não é competência essencial dos Correios ou do Bradesco, essa atividade ficou a cargo da Embratel, que projetou e criou uma unidade para gerenciar exclusivamente a rede corporativa da ECT.

Para que pudesse tornar-se uma empresa ágil e moderna no segmento financeiro, a ECT foi em busca de uma infraestrutura operacional suportada por Tl. Foi incorporado o SAA (Sistema de Automatização do Atendimento), substituído pelo sistema SARA (Sistema de Automatização da Rede de Atendimento dos Correios). Foram implantados equipamentos e sistemas para a automação do atendimento nos guichês das agências. Paralelamente, os Correios instalaram equipamentos de autoatendimento nas agências alocadas em shopping centers e aeroportos.

Finalmente, para entrar no segmento de certificação digital, a parceria com o SERPRO (Serviço de Processamento de Dados) foi decisiva, pois a ECT não possuía capacidade técnica e experiência no desempenho da prestação desse serviço.

Dada a incerteza imanente às decisões estratégicas, os seus resultados só são de fato conhecidos ex post, isto é, só ex post é que se pode afirmar se uma estratégia foi ou não acertada. No que tange especificamente ao objeto dessa análise, a ECT, os resultados são apresentados na próxima seção.

\section{Resultados da mudança de estratégia}

A estratégia de diversificação não alcançou plenamente o objetivo de reduzir a dependência da empresa em relação aos segmentos tradicionais - mensagem, encomenda, conveniência e internacional -, conforme pode ser constatado pela análise da Tabela 1.

Os novos segmentos corresponderam, no período 2003 a 2006, em média, a 18,23\% da receita da ECT. Quando se compara a participação percentual do segmento tradicional, no início da década de 1990 (92\%), com a participação em 2006, observa-se que essa dependência diminuiu em aproximadamente dez pontos percentuais. Tal fato pode ser explicado diante do caráter recente dos novos segmentos e da dificuldade de adaptação da burocracia estatal aos novos serviços. 
Tabela 1. Evolução da Receita 2003-2006 (Valores em milhões a preços de 1995).

\begin{tabular}{crrrrrrrrr}
\hline \multirow{2}{*}{ Segmentos } & \multicolumn{2}{c}{2003} & \multicolumn{2}{c}{2004} & \multicolumn{2}{c}{2005} & \multicolumn{2}{c}{2006} \\
\cline { 2 - 9 } & Valor & \multicolumn{1}{c}{$(\%)$} & Valor & $(\%)$ & Valor & \multicolumn{1}{c}{$(\%)$} & Valor & $(\%)$ \\
\hline Mensagem & 1.495 & 48,97 & 1.653 & 50,83 & 1.852 & 50,60 & 2.012 & 51,60 \\
Encomenda & 761 & 24,92 & 794 & 24,43 & 936 & 25,57 & 975 & 25,00 \\
Internacional & 117 & 3,86 & 119 & 3,67 & 122 & 3,33 & 105 & 2,70 \\
Conveniência & 103 & 3,37 & 96 & 2,97 & 102 & 2,78 & 96 & 2,47 \\
Subtotal & 2.476 & 81,12 & 2.662 & 81,90 & 3.012 & 82,28 & 3.188 & 81,77 \\
Marketing direto & 342 & 11,22 & 337 & 10,37 & 360 & 9,83 & 378 & 9,69 \\
Malote corporativo & 159 & 5,20 & 162 & 4,94 & 176 & 4,80 & 206 & 5,29 \\
Digital & 0 & 0 & 0 & & 0,6 & 0,02 & 0 & 0 \\
Logística integrada & 6 & 0,16 & 10 & 0,29 & 19 & 0,52 & 30 & 0,76 \\
Banco Postal & 70 & 2,29 & 81 & 2,50 & 92 & 2,55 & 98 & 2,51 \\
Subtotal & 577 & 18,87 & 590 & 18,10 & 648 & 17,72 & 712 & 18,25 \\
Total & 3.053 & 100,00 & 3.252 & 100,00 & 3.660 & 100,00 & 3.900 & 100,00 \\
\hline
\end{tabular}

Fonte: ECT, Relatórios anuais da Administração (2003 a 2006).

Vale destacar que, nesse período, a função social dos Correios foi ampliada, passando a participar da distribuição de livros escolares e remédios, além do recebimento de solicitações de aposentadoria e recadastramento dos segurados do INSS.

0 marketing direto é o principal negócio da estratégia de diversificação, seguido, em ordem decrescente, do malote corporativo, do Banco Postal, da logística integrada e, finalmente, da certificação digital.

O Banco Postal, desde sua implantação em 2002, atingiu a marca de 5 milhões de contas abertas, superando a expectativa de mais de 1 milhão de contas/ano e cerca de R 1 bilhão em depósitos por mês. O Banco Postal - Correspondente Bancário, por meio da prestação de serviços bancários básicos, operado em mais de 5.500 agências dos Correios, vem contribuindo para o crescimento da receita e, de modo especial, para a ampliação dos recursos/das competências da empresa, no âmbito da automatização das operações e do controle das agências, de forma integrada. A introdução do sistema Sara permitiu eficiência na entrada de dados, na prestação de contas e na reformulação da plataforma computacional (mainframe para sistema distribuído).

Quanto à logística integrada, embora com participação ainda reduzida, aumentou em quatro vezes a sua contribuição ao faturamento da empresa no período 2003-2006. A expectativa da Administração Central é de que deverá, futuramente, aumentar sobremaneira sua contribuição para 0 faturamento. A esse respeito a Tabela 2 ilustra as perspectivas dos novos segmentos para o período 2008-2011, tendo por referência o Planejamento estratégico 2008-2017, elaborado em maio de
2007. Por exemplo, espera-se que a contribuição da logística integrada, da ordem de 0,76\% em 2006, atinja 1,70\% em 2011.

A entrada da ECT no negócio de logística integrada tem caráter estratégico. Os objetivos estão perfeitamente alinhados com a visão e as metas da empresa expressas no Plano estratégico para $O$ período 2000-2005 (ECT, 1999). A recomendação estratégica "desenvolver soluções de logística integrada" aparece várias vezes, como meio de garantir o crescimento do faturamento e aumentar a rentabilidade da empresa. Ademais, ainda segundo o plano:

Atuar de forma independente como um novo negócio não prejudica a "defesa" dos negócios tradicionais da empresa, pelo contrário, ajuda a defender com mais força os negócios tradicionais (notadamente encomendas), além de permitir à ECT vislumbrar uma nova série de oportunidades.Um exemplo claro é a atuação com a Natura, que, mostrando-se interessada em uma solução logística para seus processos de recebimento de pedidos, já acena com a possibilidade de negociar parte da entrega de suas encomendas com a (ECT, 1999, p. 13).

Com relação à certificação digital, dada a sua implantação muito recente, não é possível avaliar sua contribuição para o faturamento da empresa, destacando-se, no entanto, a oportunidade para ampliar sua linha de negócios no ambiente virtual.

Enfim, embora sem reduzir plenamente a sua dependência em relação aos segmentos convencionais de atuação, a ECT ajustou-se às expectativas e exigências do ambiente institucional e, sem prejuízo de sua função social, buscou com a diversificação de suas atividades explorar a vantagem de uma rede de atendimento e de distribuição em todo o território nacional. Além 
Tabela 2. Estimativa de receita - 2007-2011.

\begin{tabular}{crrrrrrrrrrr}
\hline \multirow{2}{*}{ Segmentos } & \multicolumn{3}{c}{2007} & \multicolumn{2}{c}{2008} & \multicolumn{2}{c}{2009} & \multicolumn{2}{c}{2010} & \multicolumn{2}{c}{2011} \\
\cline { 2 - 11 } & \multicolumn{1}{c}{ Valor } & (\%) & Valor & \multicolumn{1}{c}{ (\%) } & Valor & \multicolumn{1}{c}{ (\%) } & Valor & \multicolumn{1}{c}{ (\%) } & \multicolumn{1}{c}{ Valor } & $(\%)$ \\
\hline Mensagem & 5.300 & 52,7 & 6.186 & 53,70 & 7.253 & 54,87 & 8.409 & 55,72 & 9.460 & 55,80 \\
Encomenda & 2.444 & 24,3 & 2.749 & 23,86 & 3.086 & 23,35 & 3.474 & 23,02 & 3.911 & 23,07 \\
Internacional & 263 & 2,61 & 280 & 2,43 & 302 & 2,28 & 314 & 2,08 & 327 & 1,93 \\
Conveniência & 270 & 2,68 & 295 & 2,56 & 322 & 2,44 & 352 & 2,33 & 386 & 2,27 \\
Subtotal & 8.277 & 82,29 & 9.510 & 82,55 & 10.963 & 82,94 & 12.549 & 83,15 & 14.084 & 83,07 \\
Marketing direto & 980 & 9,74 & 1.108 & 9,61 & 1.250 & 9,46 & 1.414 & 9,37 & 1.603 & 9,45 \\
Malote corpotativo & 463 & 4,60 & 508 & 4,41 & 556 & 4,21 & 610 & 4,04 & 669 & 3,94 \\
Digital & 0,8 & 0,01 & 1,4 & 0,001 & 1,6 & 0,01 & 1,8 & 0,01 & 2,3 & 0,01 \\
Logística integrada & 123 & 1,22 & 152 & 1,32 & 187 & 1,41 & 231 & 1,53 & 285 & 1,68 \\
Banco Postal & 213 & 2,12 & 240 & 2,08 & 259 & 1,96 & 284 & 1,88 & 310 & 1,82 \\
Subtotal & 1.780 & 17,69 & 2.009 & 17,43 & 2.254 & 17,05 & 2.541 & 16,83 & 2.869 & 16,90 \\
Total & 20.114 & 100,00 & 23.039 & 100,00 & 26,433 & 100,00 & 30.180 & 100,00 & 33,907 & 100,00 \\
\hline
\end{tabular}

Fonte: ECT, Planejamento estratégico 2008-2017: cenário estratégico (2007).

do papel de agente da ação governamental com os cidadãos, transformou-se em parceira de grandes empresas interessadas em viabilizar a distribuição de seus produtos por meio da oferta de serviços atrelados ao malote corporativo, ao marketing direto e à logística integrada. Agregue-se a entrada no mercado bancário por meio do Banco Postal.

\section{Conclusão}

A análise do processo de diversificação da ECT no período 2003-2006, a partir da identificação do portfólio de recursos/competências e de sua relação com o tipo e a natureza dos novos segmentos de atuação, deixou patente que

- os segmentos malote corporativo e marketing direto constituem uma extensão dos serviços tradicionais dos Correios, apoiando-se em competências preexistentes;

- a entrada nos segmentos Banco Postal e logística integrada está associada ao desenvolvimento de novos recursos e competências.

A pesquisa confirma, assim, a proposição de Frechet e Pardo (2005). 0 processo de diversificação na direção da incorporação de novos domínios pela empresa obedece a duas lógicas: utilização de recursos e competências preexistentes para entrar em novos produtos/mercados e entrada em novos produtos/mercados para o desenvolvimento de novos recursos/novas competências. Em ambos os casos, os recursos explicam as decisões de diversificação, de modo que a questão central é a integração, em um contexto dinâmico, dos efeitos da entrada em novos produtos/mercados e do desenvolvimento de novos recursos (conhecimento) sobre a perfomance da empresa.
Nessa direção, dois pontos são fundamentais.

Em primeiro lugar, se um dos propósitos da diversificação é a aprendizagem, a pesquisa deixou claro que a acumulação de recursos deve ser inserida, ao lado da contribuição para o crescimento da receita, como medida relevante para analisar o sucesso da estratégia. 0 segmento de logística integrada, embora com uma contribuição ainda reduzida para o faturamento da ECT, levou ao desenvolvimento de um conjunto de competências inéditas no âmbito da gestão de armazéns, do controle de inventários, das soluções associadas à tecnologia da informação, dos sistemas de transporte, localização e rastreamento de cargas, dos sistemas de inteligência logística e dos processos de negociação e comercialização. 0 segmento Banco Postal, por sua vez, por meio da implantação do sistema Sara, levou à automatização da rede de atendimento dos Correios, possibilitando o controle das agências de forma integrada.

Em segundo lugar, em decorrência do exposto, pode-se argumentar que um fator dinâmico crucial na evolução da corporação é a interdependência ou interação no tempo entre a diversificação de negócios relacionada aos recursos e à diversificação de recursos. Assim, além de aumentar muito a credibilidade e a reputação da ECT, como expert do negócio, a logística integrada é fundamental para proteger e desenvolver os negócios tradicionais da empresa, notadamente encomendas, e os novos negócios, como o marketing direto e o e-commerce. Por sua vez, a implantação do sistema Sara atrelado ao Banco Postal possibilitou a criação de novos serviços e a informatização dos serviços tradicionais, tais como telegrama eletrônico e via internet, aviso de recebimento (AR) digital, CPF on-line e cartão magnético para pagamento de contribuições do INSS. 
Em síntese, existe uma relação dinâmica entre os recursos (competências) - no caso da ECT, ampla cobertura geográfica, habilidades em transporte e entrega -, o processo de diversificação e a performance da empresa. A acumulação de recursos e competências ao longo do tempo influencia o processo de diversificação, favorecendo a denominada diversificação relacionada. Por sua vez, o processo de diversificação leva à acumulação de novos conhecimentos, que impele à entrada em novas e diferentes atividades relacionadas.

Cabe registrar que uma das limitações desta pesquisa diz respeito à necessidade do maior aprofundamento do processo de interação no tempo entre a diversificação de negócios relacionada aos recursos e a diversificação de recursos. Uma vez que se apoiou na pesquisa documental, não incorporou à análise as percepções/impressões dos atores estratégicos da empresa, o que contribuiria significativamente para melhor delinear esse ponto, além de abrir espaço para outras constatações derivadas do levantamento de dados com os tomadores de decisão.

Nesse sentido, abrem-se novas oportunidades de pesquisa, em primeiro lugar, na direção da superação da lacuna metodológica apontada acima, focando no processo de tomada de decisões, como ênfase em entrevistas com os principais gerentes envolvidos. Em segundo, investigação nas demais prestadoras de serviços públicos, possibilitando uma análise comparativa de desempenho por meio de constatações de similaridades e diferenças entre essas organizações. Em terceiro lugar, a replicação da proposição e da metodologia para outros ramos, em particular o industrial. E em quarto, analisar o processo de implementação da estratégia de diversificação, enfocando a identificação de estruturas e mecanismos processuais favoráveis ao compartilhamento de recursos/competências entre diferentes unidades de negócio.

\section{Referências}

BAIN \& COMPANY. Estudo de viabilidade para atuação da ECT em logística integrada. Brasília, 2003. Relatório mimeografado.

BARNEY, J.; WRIGHT, M.; KETCHEN, D. J. The resourcebased view of the firm: ten years after 1991. Journal of Management, v. 27, n. 6, p. 625-641, 2001.

BETTIS, R. A.; MAHAJAN, V. Risk/return performance of diversified firms. Management Science, v. 31, n. 10, p. 785-799, 1985.

DESS, G. G. et al. Conducting and integrating strategy research at the international, corporate, and business levels: issues and directions. Journal of Management, v. 21, n. 2, p. 357-393, 1995.
EMPRESA BRASILEIRA DE CORREIOS E TELÉGRAFOS ECT. Relatório anual da Administração. Brasília, 1995. Relatório mimeografado.

Relatório anual da Administração. Brasília, 1996. Relatório mimeografado.

Relatório anual da Administração. Brasília, 1997. Relatório mimeografado.

Relatório anual da Administração. Brasília, 1998. Relatório mimeografado.

Relatório anual da Administração. Brasília, 1999. Relatório mimeografado.

. Relatório anual da Administração. Brasília, 2000. Relatório mimeografado.

Relatório anual da Administração. Brasília, 2001. Relatório mimeografado.

Relatório anual da Administração. Brasília, 2002. Relatório mimeografado.

Relatório anual da Administração. Brasília, 2003. Relatório mimeografado.

Relatório anual da Administração. Brasília, 2004. Relatório mimeografado.

Relatório anual da Administração. Brasília, 2005. Relatório mimeografado.

Relatório anual da Administração. Brasília, 2006. Relatório mimeografado.

Estrutura da ECT. Brasília, 1995. Disponível em: <http://www.correios.com.br/nossahistoria.html>. Acesso em: 19 set. 2007.

. Plano estratégico para o periodo 2000-2005. Brasília, 1999. Relatório mimeografado.

. Plano estratégico 2004-2007 (Revisão 2007). Brasília, maio 2007a. Relatório mimeografado.

Planejamento estratégico 2008-2017: cenário estratégico. Brasília, 2007b. Relatório mimeografado.

FAN, J. H.; LANG, L. H. P. The measurement of relatedness: an application to corporate diversification. Journal of Business, v. 73, n. 4, p. 629-660, 2000.

FOSS, N. J. Resources and strategy: a brief overview of themes and contributions. In: FOSS, N. J. (Ed.). Resources, firms and strategies: a reader in the resource-based perspective. Nova York: Oxford University Press, 1997. p. 1-17.

FRECHET, M.; PARDO, D. Resource-driven diversification: assessing relatedness through competence analysis. 2005. Disponível em: <http://www.iae-toulouse.fr>. Acesso em: 20 jan. 2008.

GAMBARDELLA, A.; TORRISI, S. Does technological convergence imply convergence in markets? Evidence from de eletronics industry. Research Policy, v. 27, n. 5, p. 445-463, 1998.

GRANSTRAND, 0.; SJOLANDER, S. Managing innovation in muli-technology corporations. Research Policy, v. 19, n. 1, p. 35-60, 1990.

GRANSTRAND, 0.; SJOLANDER, S.; ALANGE, S. Strategic technology issues in japanese manufacturing industry. Technology Analysis \&t Strategic Management, v. 1, n. 4, p. 259-272, 1989.

GRANSTRAND, 0.; OSKARSSON, C. Technology diversification in "mul-tech" corporations. IEEE Transactions on Engineering Management, v. 41, n. 4, p. 355-364, 1994. 
HAMILTON, R. T.; SHERGILL, G. S. Extent of diversification and company performance: the New Zealand evidence. Managerial and Decision Economics, v. 14, n. 1, p. 47-52, 1993.

HITT, M. A.; IRELAND, R. D. Relationships among corporate level distinctive competences, diversification strategy, corporate structure and performance. Journal of Management Studies, v. 23, n. 4, p. 401-416, 1986.

MARKIDES, C.; WILLIAMSON, P. J. Related diversification, core competences and corporate performance. Strategic Management Journal, v. 15, p. 149-165, 1994.

McDOUGALL, F. M.; ROUND, D. K. A comparison of diversifying and non diversifying Australian manufacturing firms. Academy of Management Journal, v. 27, n. 2, p. 384-398, 1984.

MILLER, D. Firms' technological resources and the performance effects of diversification: a longitudinal study. Strategic Management Journal, v. 25, n. 11, p. 1.097-1.119, 2004.

PALEPU, K. Diversification strategy, profit performance and the entropy measure. Strategic Management Journal, v. 6, n. 3, p. 239-255, 1985.

PENROSE, E. T. A teoria do crescimento da firma. Tradução de Tamás Szmrecsányi. Campinas: Editora da Unicamp, 2006.

PETERAF, M. A. The cornerstones of competitive advantage: a resource-based view. Strategic Management Journal, v. 14, n. 3, p. 179-191, 1993.
PISCITELLO, L. Corporate diversification, coherence and economic performance. Industrial and Corporate Change, v. 13, n. 5, p. 757-787, 2004.

RAMANUJAM, V; VARADARAJAN, P. Research on corporate diversification: a synthesis. Strategic Management Journal, v. 10, n. 6, p. 523-551, 1989.

RUMELT, R. P. Strategy, structure and economic performance. Cambridge: Harvard University Press, 1974.

Diversification strategy and profitability. Strategic Management Journal, v. 3, n. 4, p. 359-369, 1982.

STEINDL, J. Maturidade e estagnação no capitalismo americano. Tradução de Leda Maria Gonçalves Maia. São Paulo: Abril Cultural, 1983.

TEECE, D. J. et al. Understanding corporate coherence: theory and evidence. Journal of Economic Behaviour and Organization, v. 23, n. 1, p. 1-30, 1994.

TEECE, D. J.; PISANO, G.; SHUEN, A. Dynamic capabilities and strategic management. Strategic Management Journal, v. 18, n. 7, p. 509-533, 1997.

WERNERFELT, B.; MONTGOMERY, C. A. Tobin's Q and the importance of focus in firm performance. American Economic Review, v. 78, n. 1, p. 246-250, 1988.

YIN, R. K. Estudo de caso: planejamento e métodos, 2 ed. Tradução de Daniel Gassi. Porto Alegre: Bookman, 2001.

\section{Competence sharing and acquisition strategy organization in Empresa Brasileira de Correios e Telégrafos - ECT (Brazilian Post Office Company)}

\section{Abstract}

Taking Frechet and Pardo's proposition (2005) as reference, this work is an explanatory study that analyzes in depth the strategy of ECT diversification, investigating how the portfolio of resources impacts on and is impacted by the decisions to enter into new domains. It deals with a case study, based on the raising of tangible and intangible assets and the evaluation of the effects of the new participating segments on company revenues. The study confirms the proposition of the reference authors, pointing towards two logics immanent to the diversification process: utilization of pre-existing resources to ingress into new products/markets, and the entering into new products/markets for the development of new resources. Therefore, it may be argued that a crucial dynamic factor in corporate evolution is the interdependency or interaction over time between business diversification related to resources and diversification of resources.

\section{Keywords}

Strategy. Diversification. Dynamic competences. 